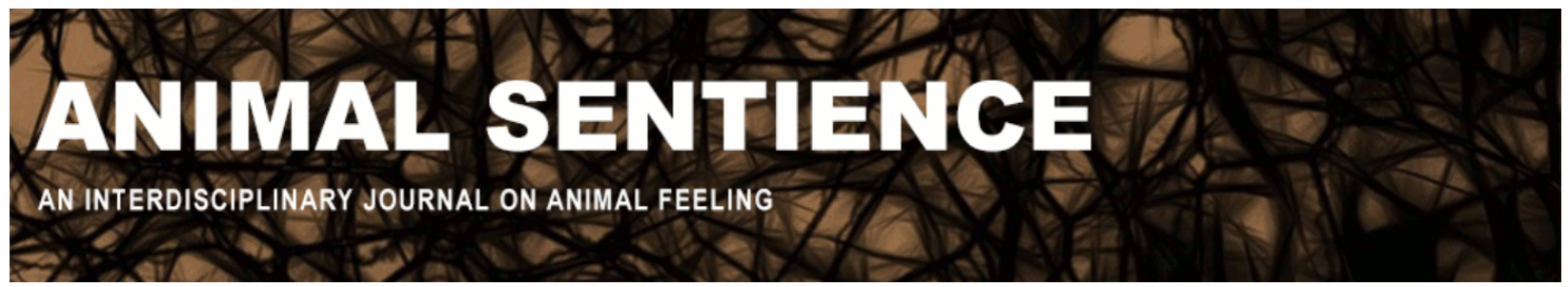

Zentall, Thomas (2017) Cognitive dissonance or contrast? It could be both. Animal Sentience 12(6)

DOI: $10.51291 / 2377-7478.1202$

Date of submission: 2017-05-11 Date of acceptance: 2017-05-25 (c) (†) 


\title{
Cognitive dissonance or contrast? It could be both
}

\author{
Response to Commentary on Zentall on Cognitive Dissonance
}

Thomas R. Zentall

Department of Psychology, University of Kentucky

\begin{abstract}
My target article suggested that cognitive dissonance may be accounted for by a simpler mechanism: contrast. Whether contrast can explain all cognitive dissonance effects is an empirical question, but it is always useful to try to distinguish simpler mechanisms from more complex cognitive ones. The insistence that cognitive dissonance is a human-only process quite different from contrast may be a self-serving means of justifying the exploitation of animals.
\end{abstract}

Thomas R. Zentall is Professor of Psychology at the University of Kentucky. His research interests focus on cognitive behaviors in animals including memory strategies, concept learning, and social learning. http://uky.edu/ zentall

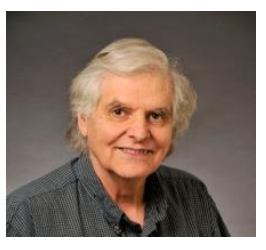

In no case may we interpret an action as the outcome of the exercise of a higher psychical faculty, if it can be interpreted as the outcome of the exercise of one which stands lower in the psychological scale. (Morgan, 1894, p. 53)

The famous quote by Conwy Lloyd Morgan (1894) has borrowed from Occam's razor the idea that simpler mechanisms can often account for the results of experiments and when they can, they are preferred. But the advantage of simpler mechanisms is not just that they are simpler but that they may provide testable alternatives against which to further test the more complex mechanism. That is, they can serve as a challenge to develop tests to distinguish between the simpler and more complex explanations. Sometimes these tests demonstrate that the simpler mechanism can adequately account for the effect, or they provide boundary conditions for the simpler account, or they may provide evidence for the more complex account, or they may raise new alternative accounts of the phenomenon being studied. In any case, these tests often advance our understanding of the phenomenon.

Such is the case with the research on cognitive dissonance or the form of cognitive dissonance called justification of effort reported in the target article (Zentall 2016). I reported the results of several experiments in which pigeons (and humans) preferred signals for reinforcement that followed less preferred events (greater effort, longer delays, and the absence of food) relative to more preferred events (less effort, less delay, and food). More important, I argued that those effects were more parsimoniously explained by contrast between the less preferred event and the signal for reinforcement. I concluded by saying that this form of contrast might also account for some of the findings reported as cognitive dissonance with 
humans, but that in any case this approach might better define the conditions under which a more complex cognitive account is needed.

The term cognitive dissonance encompasses a broad range of behavior which paradoxically appears to be inconsistent with the typical negative relation between aversive events and preference. The research presented in the target article provided an analog for one kind of cognitive dissonance research, justification of effort. But as noted, other kinds of cognitive dissonance may also be relevant. For example, in the original cognitive dissonance experiment, humans were asked to reflect back on the aversiveness of a previous task (Festinger \& Carlsmith, 1959) after being paid a small or larger amount to report to a waiting participant that the task was interesting. It was argued that there was more contrast between the larger payment and the uninteresting task than with the small payment. Such an experiment would be difficult to attempt with non-verbal animals.

More appropriate for the within-trial contrast effect described in the research presented in the target article are results demonstrating that justification of effort effects depend on how the aversive event is related to the task itself. For example, E. Harmon-Jones (2017) notes that Gerard \& Mathewson (1966) found that participants who experienced intense shocks evaluated a group to which they thought they would gain access more positively than participants who experienced mild shocks. But they did so only when participants were led to believe that they were receiving the shocks in order to gain access to the group. That is, when the shocks were viewed as independent of group initiation, no cognitive dissonance effect was found. Although E. Harmon-Jones interpreted these results as evidence against the contrast account, such results merely help define the conditions under which the contrast effect will occur.

As noted by E. Harmon-Jones as well as C. Harmon-Jones et al. (2017), humans are different from other animals in the sense that instructions can be used to override their interpretation of the temporal occurrence of events. That is, if humans are told that two events they have experienced - the shock and the group initiation - are not related, an association between them is much less likely to occur. It is hard to imagine how one would give such instructions to pigeons. Thus for pigeons it would be very difficult to disassociate the prior effort from the value of the conditioned reinforcer that follows. For this reason, contrary to E. Harmon-Jones's suggestion that a contrast explanation predicts that the association between the aversive event and reward that follows would not matter, the association does matter for pigeons and it does matter for humans as well - unless they are told otherwise. It would be difficult, however, to eliminate that association with nonhuman animals because of the difficulty in telling them that the events are not related.

E. Harmon-Jones goes on to ask a related question: Why is it that contrast occurs with the procedures we use in our studies when the relationship between effort and reward evaluation is often quite the opposite. That is, in many cases, greater effort leads to reward devaluation or effort discounting. For example, Botvinick et al. (2009) found that participants showed reduced brain activity in reward centers (nucleus accumbens) when rewards were preceded by high effort. Why do aversive events sometimes devalue the rewards that follow (resulting in generalization) and at other times enhance those rewards 
(resulting in contrast)? I suspect that the answer lies in whether and how much the prior effort is associated with the reward. In fact, in that experiment, participants were told that the amount they would earn would be equal for high- and low-effort blocks, and would not depend on their speed or accuracy. Thus, instructions to humans about the relation between the effort and reward can determine whether there will be contrast or generalization.

As noted by E. Harmon-Jones, Festinger believed that his theory also applied to the behavior of nonhuman animals (Lawrence \& Festinger, 1962). The examples provided by Lawrence \& Festinger, however, are only remotely related to the cognitive-dissonance research that had been conducted with humans and the justification-of-effort results we have reported with pigeons. In fact, the results they described are easily accounted for by much simpler behavioral mechanisms. For example, they cite the partial reinforcement extinction effect in which, paradoxically, discriminations in which correct responses are reinforced only half of the time are more difficult to extinguish than when correct responses are reinforced every time. The partial reinforcement extinction effect, however, has been attributed to a generalization decrement (extinction is more difficult to detect if training has involved a series of non-reinforced correct responses; Capaldi, 1967) or to the response unit hypothesis (in which the reinforced response is the sequence of responses that preceded reinforcement during training; Mowrer \& Jones, 1945).

As noted in the conclusion of the target article, although justification of effort may be based on simpler, less cognitive contrast, it does not rule out the possibility that more complex, cognitive dissonance effects are also involved. The purpose of the target article was to ask to what extent contrast effects can account for results that have been attributed to conflicting cognitions that produce dissonance. The effort to distinguish between different theories is what allows our science to advance beyond theories that are primarily descriptive, to theories that can better explain behavior.

The commentary of Vonk (2017) makes the reasonable argument that nonhuman animals may engage in behaviors similar to those of humans for very different underlying reasons. This is always a possibility, but the apparent similarity encourages researchers to explore the conditions under which the more cognitive accounts are necessary. The effect of instructions to dissociate the prior aversive activity from the later preference judgment (Gerard \& Mathewson, 1966) suggests one way that the effects with pigeons may be different from those with humans.

Vonk finds it "puzzling that animals would prefer a cue that signaled the lack of food" but the cue does not signal the absence of food. It simply follows the absence of food and that contrast makes it preferred over a cue that follows the presence of food. Vonk also suggests that the contrast effect described in the target article might be related to the cognitive bias paradigm. In the cognitive bias paradigm (e.g., Burman et al. 2011), animals are trained, for example, to associate one brightness value with food and another brightness value with the absence of food. Then, after receiving or not receiving a reward, the animals are tested with intermediate brightness values. Slower responses to the intermediate rewards have been interpreted as showing a pessimistic (rather than an optimistic) bias but a more parsimonious interpretation is that the prior feeding affected the animals' motivation. In this 
case, the animals showed a longer latency to the middle-valued brightness after having been fed. Distinguishing motivational effects from affective (optimism versus pessimism) effects presents an important challenge to researchers interested in the cognitive bias paradigm.

Also mentioned in the target article was the choice-induced preference effect (or the spreading-of-alternatives effect) in which, given a choice between two alternatives, the one that was not selected appears to acquire aversive properties relative to a novel alternative. This effect has been viewed as an example of cognitive dissonance but it is not directly related to justification of effort effect and so probably should not have been included in the target article. Chen and Risen (2010) viewed the choice-induced preference effect as an artifact of "revealed preferences" among the three alternatives. They argued that just by chance, natural preferences would produce such a bias; however, as is noted by E. HarmonJones as well as by C. Harmon-Jones et al. and Eisenreich \& Hayden (2017), but neglected in the target article, evidence against the revealed preferences hypothesis was provided by research showing that choice-induced preference could be found even when subjects did not actually choose between the first two alternatives. What still needs to be ruled out, however, is the possibility that preference for the third alternative over the unchosen alternative results from a preference for novelty over familiarity because the non-selected alternative was familiar and the new (third alternative) was novel. In any event, the choice-induced preference may be unrelated to the justification of effort, and its discussion would have been more appropriately reserved for a different time.

Finally, C. Harmon-Jones et al. propose that the motivation to "humanize" humans and "dehumanize" nonhuman animals itself may be relevant to dissonance theory: The insistence that cognitive dissonance is a human-only process quite different from contrast may be a self-serving means of justifying the exploitation of animals. This clever twist on several of the commentaries shifts the focus from the research on cognitive dissonance to the motivation of the cognitive dissonance researcher who may have a vested interest in the distinction between humans and other animals.

The intent of the target article was to suggest that the basis of cognitive dissonance may be a form of contrast, a simpler mechanism. Whether contrast can account for all cognitive dissonance effects that have been reported is an empirical question. More broadly, the search for tests to distinguish simpler from more cognitive mechanisms has value not only in establishing the underlying basis for the phenomena in question but also in helping to better define and understand the causes of behavior.

\section{References}

Botvinick, M. M., Huffstetler, S., \& McGuire, J. T. (2009). Effort discounting in human nucleus accumbens. Cognitive, Affective, \& Behavioral Neuroscience, 9, 16-27.

Burman, O., McGowan, R., Mendl, M., Norling, Y., Paul, E., Rehn, T., \& Keeling, L. (2011). Using judgement bias to measure positive affective state in dogs. Applied Animal Behaviour Science, 132, 160-168. 
Capaldi, E. J. (1967). A sequential hypothesis of instrumental learning. In K. W. Spence \& J. T. Spence (Eds.), The psychology of learning and motivation (Vol. 1, pp. 67-156). New York: Academic Press.

Chen, M. K., \& Risen, J. L. (2010). How choice affects and reflects preferences: Revisiting the free-choice paradigm. Journal of Personality and Social Psychology, 99, 573-594.

Eisenreich, B. R., \& Hayden, B. Y. (2017). Choice-induced preference: A challenge for contrast. Animal Sentience 12(3).

Festinger, L., \& Carlsmith, J. M. (1959). Cognitive consequences of forced compliance. Journal of Abnormal and Social Psychology, 58, 203-210.

Gerard, H. B., \& Mathewson, G. C. (1966). The effects of severity of initiation on liking for a group: A replication. Journal of Experimental Social Psychology, 2, 278-287.

Harmon-Jones, C., Haslam, N., \& Bastian, B. (2017). Dissonance reduction in nonhuman animals: Implications for cognitive dissonance theory. Animal Sentience 12(4).

Harmon-Jones, E. (2017). Clarifying concepts in cognitive dissonance theory. Animal Sentience 12(5).

Lawrence, D. H., \& Festinger, L. (1962). Deterrents and reinforcement. Stanford, CA: Stanford University Press.

Morgan, C. L. (1894). An introduction to comparative psychology. London: W. Scott.

Mowrer, O. H., \& Jones, H. (1945). Habit strength as a function of the pattern of reinforcement. Journal of Experimental Psychology, 35, 293-311.

Vonk, J. (2017). What can research on nonhumans tell us about human dissonance? Animal Sentience 12(2).

Zentall, T. R. (2016). Cognitive dissonance or contrast? Animal Sentience 12(1). 